\title{
Effect of Machining Parameters on Tool Life and Surface Roughness of AISI 1040 Dual Phase Steel
}

\author{
Gurumurthy BMa ${ }^{a}$, Jamaluddin Hindi ${ }^{a}$ * (1), Ananda Hegde ${ }^{a}$ (D), Sathyashankara Sharma ${ }^{a}$ (1), \\ Achutha Kini ${ }^{a}$ \\ ${ }^{a}$ Manipal Institute of Technology, Manipal Academy of Higher Education, Department of Mechanical
and Manufacturing Engineering, 576104, Manipal, India.
}

Received: July 10, 2021; Revised: September 09, 2021; Accepted: October 08, 2021

\begin{abstract}
The purpose of this research is to investigate the effect of heat treatment parameters on the tool life and surface roughness of dual phase steel. Optimization of machining parameters (cutting speed, feed and depth of cut) is carried out for the machinability tests on medium carbon low alloy steel. Taguchi's method of design is used to carry out machinability tests. Analysis of variance (ANOVA) is carried out to determine the relative contribution of machining parameters on tool life and surface roughness. Microstructure analysis is carried out to ascertain the machining behavior of the steel. Results have shown that, depth of cut and cutting speed are the most significant factors contributing on the variation of the tool life and surface roughness. Optimized machining parameters are calculated in order to obtain higher tool life and lower surface roughness value.
\end{abstract}

Keywords: Ferrite, bainite, martensite, dual phase, AISI1040.

\section{Introduction}

Machinability of material plays an important role in the industry to improve their manufacturing capacity and to reduce the cost of the component. Dual phase microstructure in a medium carbon and/or alloyed steel provides not only a high strength, but also a good formability and yielding without serrations ${ }^{1}$. In this type of microstructure, soft ferrite and hard martensite phases are present which induces the ductility and the strength for the steel. The medium carbon low steel property can be easily altered by giving suitable heat treatment process ${ }^{2}$. Heat treatment process involves the heating, soaking, holding and cooling in different temperature and coolants ${ }^{3}$. The improvement in the mechanical properties via forming a dual phase microstructure in the steel supplies the benefit of reducing the weight of systems ${ }^{4}$. The studies on dual phase steels (DPS) have been focused generally on the microstructural and mechanical characterizations after intercritical heat treatment applications ${ }^{5}$. On the other hand, the machinability of these materials is also very important property which should be focused on.

Especially low carbon and medium carbon steel may be produced with dual phase structure. During heat treatment, it is possible to alter the mechanical properties of the material by obtaining the suitable microstructure as per the requirements $^{6}$. Iron has a higher solubility for carbon in the austenite phase. Formation of dual phase in medium carbon steel depends on the intercritical temperature range. Dual phases may be ferrite with martensite (F-M) or ferrite with a bainite $(\mathrm{F}-\mathrm{B})^{7}$. Generally, in a dual phase condition, hardness property will increase due to the increasing dissolution time and increase in temperature ${ }^{8}$. This research aims to assess the

*e-mail: jamaluddin.hindi@manipal.edu machinability of medium carbon low alloy DPS which was subjected to dual phase (F-B) treatment. Dual phase treatment is carried out by varying the intercritical temperatures from 750,770 and $790^{\circ} \mathrm{C}$. The effect of both dual phase structure on machinability is studied and optimum tool life $\left(\mathrm{T}_{\mathrm{L}}\right)$ along with surface roughness $\left(\mathrm{S}_{\mathrm{R}}\right)$ values have been determined.

The machinability of these materials is also very important, particularly with respect to the martensite fraction. Optimum cutting parameters in machining should be determined for dual-phase steels with respect to the martensite fraction and the tool types. This knowledge would be very helpful for accelerating the machining process and improving the $T_{L}$ and $S_{R}$, with the lower power consumption, less usage of material and less amount of fluid consumption ${ }^{9}$. Some of the authors compared dry condition machining with the wet condition machining operation using different cutting tools and they have suggested that carbide cutting tool gives longer $\mathrm{T}_{\mathrm{L}}$ compared to other tools ${ }^{10}$. Another author suggested that better $S_{R}$ as well as optimum $T_{L}$ can be achieved by using carbide cutting tools ${ }^{11}$.

The effect of cutting variables on MRR and tool wear for EN8 steel has been investigated ${ }^{12}$. High speed steels and carbide tip tools are widely used for cutting. Hardness, wear resistance, thermal stability and strength are the cutting variables that influence the efficiency of the tool. Cemented carbides are used due to their high hot hardness and wear resistance while low toughness being their main disadvantage. The wear resistance of EN-8 steel can be enhanced by using surface hardening techniques. The increase in speed, feed or depth of cut (DoC)leads to higher tool wear and higher the spindle speeds the higher the MRR ${ }^{13}$. studied the single response optimization of turning parameters for EN-8 steel to 
optimize the $\mathrm{S}_{\mathrm{R}}$ and tool tip temperature in turning operations using single point carbide cutting tool. Optimum values of speed and depth of cut were obtained using L9 orthogonal array and ANOVA (Analysis of variance) was employed to analyze the effects of the process parameters during turning. Mathematical tools like Signal to noise ratio $(\mathrm{S} / \mathrm{N})$ and Variance was analyzed using Taguchi method to understand the effect of different machining parameters on $\mathrm{S}_{\mathrm{R}}$ and tool tip temperature values. Experimentation revealed that $S_{R}$ is directly proportional to increase in speed but inversely to increase in depth of cut and tool tip temperature is directly proportional to both speed and depth of cut. The effect of cutting parameters on the flank wear during CNC (with a maximum spindle speed of $4000 \mathrm{rpm}$ ) turning of EN8 steel has discussed. Three different types of tool inserts used are uncoated carbide insert (GRADE: TTS), uncoated carbide insert (GRADE: TTR) and coated carbide insert (GRADE: K10U). Flank wear behavior is little varied for different speeds and feeds and is a complex function of both the parameters. It was also observed that the coated type of tool insert K10U showed the minimum flank wear out of the three different types of tool inserts used and thus has the longest $\mathrm{T}_{\mathrm{L}}$ in these cutting conditions. In addition, it was observed that optimum conditions to get minimum flank wear are medium speed and medium feed rate ${ }^{14}$. The optimization of machining parameters like speed, feed and depth of cut for EN-8 steel with a tungsten carbide tip tool was discussed. Statistical analysis through Taguchi method is used to find the optimum range of speed, feed and depth of cut to minimize the surface roughness. First phase is the machining of the selected work piece and tools using conventional methods where time and final weight are noted while the second phase is the analysis of machined work pieces and tool. MRR and tool wear rate are calculated and SEM test helps in understanding the property of machined surface. Taguchi method is used as it allows us to modify the time factor and yet evaluate the influence of each factor and it allows us to experiment in limited number and predict the remaining permutations of factors. The optimized results showed that optimum speed is $450 \mathrm{rpm}$, feed is $0.110 \mathrm{~mm} / \mathrm{rev}$ and depth of cut is $1.2 \mathrm{~mm}^{15}$. The optimization process will help to improve $S_{R}$ and optimum amount of material removal rate which increases the $\mathrm{T}_{\mathrm{L}}{ }^{16}$.

The influence of machining parameters like cutting speed, depth of cut and feed on EN-8 steel for MRR in multiple operations like turning, facing operations reported. Different experiments are conducted for the various experimental runs and the experimental results lead to the formulation of empirical equation, through which predicted value of MRR is calculated. Genetic algorithm is used to solve the empirical equation. The optimal speed value for MRR is $800 \mathrm{rpm}$ while the optimum feed value is $0.1 \mathrm{~mm} / \mathrm{rev}$. The genetic algorithm also finds the best fitness value as $0.326107 \mathrm{~g} / \mathrm{sec}$ and one can see that MRR is directly proportional to feed rate and spindle speed ${ }^{17}$. The detailed analysis of $\mathrm{S}_{\mathrm{R}}$ in dry machining of EN-8 steel was reported. Regression models are created for $\mathrm{Ra}, \mathrm{Rq}$, and $\mathrm{Rz}$ parameters of surface topology, which are important parameters from contact stiffness, fatigue strength and surface wear perspective. Taguchi method was used in the experiments, for the three factors at three levels. It is discovered that the percent errors are little for regression modes when contrasted with geometrical model. The results of the experiments show clearly that there is no significant difference in the $S_{R}$ in dry machining as compared to machining with a coolant ${ }^{18}$. In another study, optimization of the process parameters like speed, depth of cut and feed are obtained to achieve the better machinability for the material which can be used in industrial application ${ }^{19}$. Few authors have also reported about wet condition machining process. In this process, more amount of oil consumption helps to improve the specific energy consumption and helps in obtaining less friction between $\mathrm{T}_{\mathrm{L}}$ and the workpiece ${ }^{20}$.

However, not many reports are available regarding the machining behavior of ferrite-martensite DPS. As this material is being used in wide range of application, understanding its machining behavior would immensely helpful for the manufacturer. In this study, machinability in terms of $T_{L}$ and $S_{R}$ for the ferrite-martensite DPS is determined. Also, in order to get the optimum combination of $T_{L}$ and surface roughness, machining parameters are obtained.

\section{Materials and Methods}

\subsection{AISI 1040 steel}

Round samples of size 100 length and $20 \mathrm{~mm}$ dia were prepared from industrial steel of the chemical composition specified in Table 1. The intercritical heat treatments at 750 , 770 and $790^{\circ} \mathrm{C}$ were carried out on these steel specimens to obtain three different martensite volume fractions. These temperatures were utilized and corresponded to low, medium and high martensite volume fractions (approximately 30, 50 and $80 \%$ ) in the steel. In addition, the normalizing treatment at $900{ }^{\circ} \mathrm{C}$ was also performed for one group of specimens to obtain a fine ferrite and pearlite microstructure to compare with the intercritically treated specimens. Three different specimen groups, according to their microstructures, were formed. After finishing the thermal treatment procedures, the martensite volume fractions in the intercritically heat treated samples were checked using an image-processing computer program.

Taguchi method is a very powerful statistical tool. It involves selecting the parameters and the factors affecting these parameters. It identifies the levels of all the factors affecting the parameters and then forms an orthogonal array. This orthogonal array shows all the possible combinations of all the factors. Program behind this Taguchi tool analyses the data and gives us the optimum sets of combinations of

Table 1. Prominent alloying elements of the medium carbon AISI 1040.

\begin{tabular}{cccccccc}
\hline \multirow{2}{*}{ Type of Steel } & \multicolumn{7}{c}{ wt.\% } \\
\cline { 2 - 8 } & $\mathbf{C}$ & Mn & Si & Cr & Mo & Ni & Fe \\
\hline AISI 1040 & 0.39 & 0.72 & 0.10 & 0.03 & 0.02 & 0.02 & Remainder \\
\hline
\end{tabular}


factors $^{21-22}$ (one or more than one optimum combination may be present).

To assess the machinability in terms of tool life, turning operation is carried out by using CNC machine and analysis of $\mathrm{T}_{\mathrm{L}}$ is obtained based on ISO 3685 standard $^{23}$. The turning operation is carried out at dry condition. Similarly, for the same condition, $\mathrm{S}_{\mathrm{R}}$ analyses is also obtained. Once the results are obtained, the data is analyzed and optimization is carried out in order to obtain the higher $T_{L}$ with lesser $S_{R}$ value.

To carry out the machinability tests, following factors are selected and varied in different levels as explained below.

Factors (F): Temperature, Speed, Feed, and Depth of cut.

No. of levels (L): 3

Therefore, according to full factorial method, total number of combinations to carry out the tests would have been, $\mathrm{L}^{\mathrm{F}}=3^{4}=81$.

However, in order to save time and experimental cost, design of experiment is used with Taguchi method. As per the Taguchi method, 27 combination of experimental trails have been obtained. $T_{L}$ and $S_{R}$ is determined in each of these trails. The turning experiments were carried out on a CNC vertical machining center (Fanuc Oi-mate TD) in dry conditions. VNMG 12 t304 insert tool was used in the turning operation of the steel specimens.

\subsection{Tool specification}

Double-sided $35^{\circ}$ rhombic inserts were used for superfinishing. Tool controls chip flow at very low feed and depth of cut. It has also got excellent crater wear resistance. The views of the tool insert used in the study is shown in Figure 1.

\section{Results and Discussion}

The present investigation mainly focuses on the effect of machining parameter on $\mathrm{T}_{\mathrm{L}}$ and $\mathrm{S}_{\mathrm{R}}$ of DPS. The results are in two phases. First phase covers the statistical analysis of $T_{L}$ and $S_{R}$ results and second phase involves combined optimization of $T_{L}$ and $S_{R}$ of DPS.

\subsection{Microstructure analysis of DPS}

Figure 2-4 show the microstructure of DPS at different intercritcal temperatures. The SEM micrographs of DPS showed that the microstructure consists of mainly ferrite and martensite at all the three intercritical temperatures. The observation from the microstructures is as the intercritical temperature increases from 750 to $790{ }^{\circ} \mathrm{C}$ there is an increase in wt. $\%$ of martensite content and decrease in ferrite wt.\% which changes the mechanical properties of material because martensite is harder in nature and ferrite is softer ${ }^{24}$. Lower intercritical temperature has lesser amount of martensite which reflects in less hardness and tends to lead higher $\mathrm{T}_{\mathrm{L}}$. But, as the intercritical temperature increases from 750 to $790{ }^{\circ} \mathrm{C}$, amount of ferrite content decrees, which leads in decrease in $T_{L}$. Similarly for the $S_{R}$, the initial intercritical temperature has lesser amount martensite which shows the poor $\mathrm{S}_{\mathrm{R}}$. However, higher the intercritical temperature has moderate martensite and ferrite which helps to increase the $\mathrm{S}_{\mathrm{R}}$ Microstructure study reveals the variation in the volume fraction of dual phases with respect to temperature which results in the improvement in machining behaviour.

Table 2 provides $T_{L}$ and $S_{R}$ values of AISI1040 F-M DPS at different temperatures and different machining parameters. Minitab is used to analyze the effect of cutting speed, feed and Depth of cut on tool $\mathrm{T}_{\mathrm{L}}$ and $\mathrm{S}_{\mathrm{R}}$ of F-M DPS.

\subsection{ANOVA for the $T_{L}$}

Tables 3 and 4 show the ANOVA results. ANOVA technique is applied, initially for all the four factors together with their interactions and it is found that all factors are linear and has more than $98 \%$ influence on $\mathrm{T}_{\mathrm{L}}$ and surface roughness. The technique is carried out at 5\% significance level using only the linear terms to obtain the relative contribution of the four factors on $T_{L}$ and $S_{R}{ }^{21-24}$.

ANOVA Table 3 shows that temperature and speed are having more contribution on the $T_{L}$. Structure of the steel will affect the $T_{L}$ because as intercritical temperature changes wt. $\%$ of ferrite and martensite also changes. As speed increases $T_{L}$ increases but depth of cut and feeds are less contribution on $\mathrm{T}_{\mathrm{L}}$.

Main effect plot shows (Figure 5) the influence of independent factors on dependent outputs. As the austenite temperature increases more quantity of austenite will be converted into martensite. Martensite is hard phase, depending on soaking period and critical cooling rate, quality of martenite changes. Slower cooling rate than the critical cooling rate makes martensite transformation amount less whereas cooling rate faster than the critical cooling rate accelerates the martensite formation process with more amount of formed martensite ${ }^{25}$. Temperature, speed and depth of cut are showing same effect
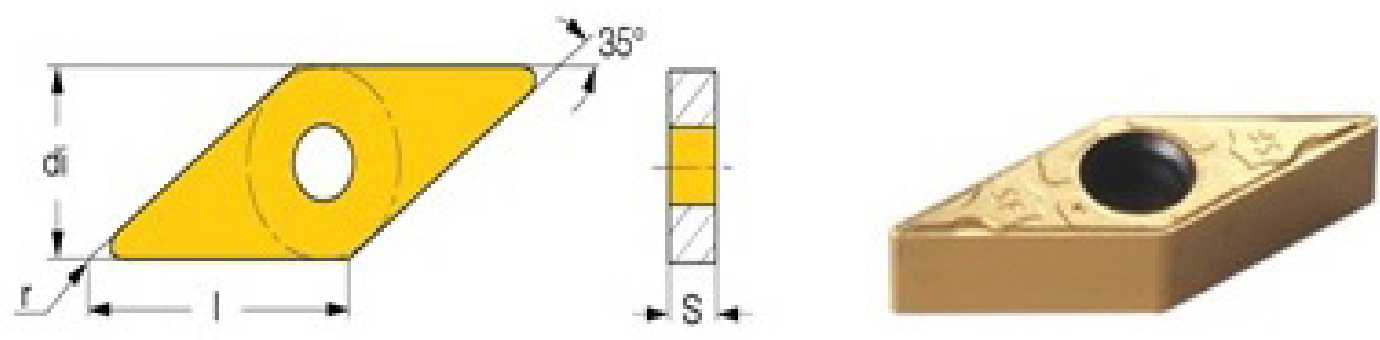

Figure 1. Silicon carbide tool. 


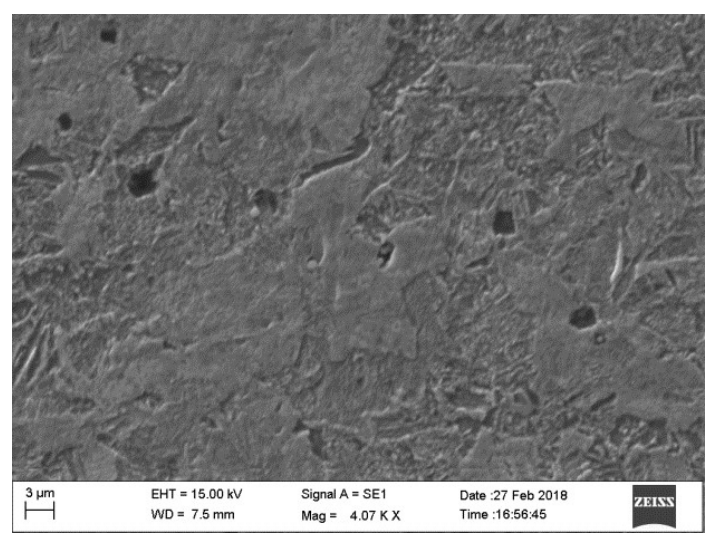

Figure 2. Ferrite-martensite DPS at $750{ }^{\circ} \mathrm{C}$.

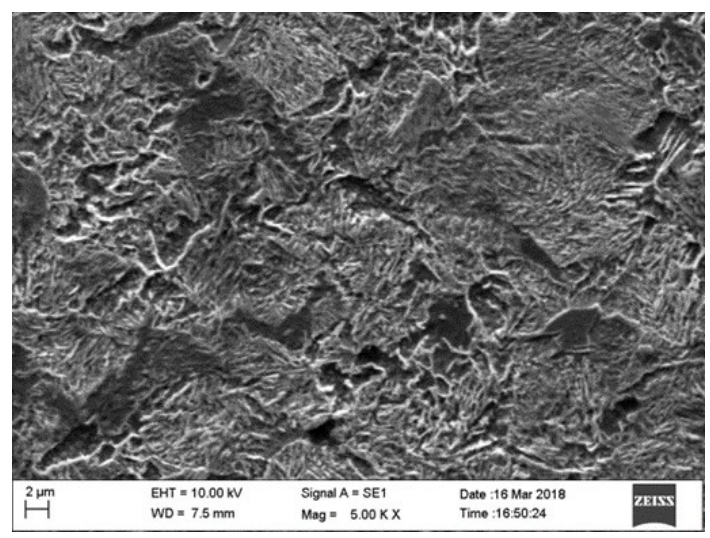

Figure 3. Ferrite-martensite DPS at $770^{\circ} \mathrm{C}$. i.e., lower temperature $\left(750{ }^{\circ} \mathrm{C}\right)$, speed $(115 \mathrm{~m} / \mathrm{min})$ and depth of cut $(0.2 \mathrm{~mm})$ conditions show better $\mathrm{T}_{\mathrm{L}}$ compared to higher temperature. But the selected feed is having least effect on the DPS.

\subsection{Analysis of variance for surface roughness}

ANOVA for $S_{R}$ p magnitude will describe the control factors significance on the $S_{R}$. At higher temperature, quantity of martensite is more that leads to lesser $T_{L}$ due to increased hardness and strength. It is seen that temperature has maximum effect on $\mathrm{S}_{R}$ with $46.54 \%$ and $38.11 \%$ contribution on $\mathrm{T}_{\mathrm{L}}$ due to increase in wt.\% of martensite content and decrease in ferrite wt. $\%$. Similarly speed also has $41.50 \%$ contribution on $\mathrm{S}_{\mathrm{R}}$ and $31.14 \%$ on $\mathrm{T}_{\mathrm{L}}$. As the cutting speed increases $\mathrm{T}_{\mathrm{L}}$ decreases and $S_{R}$ increases. Feed has least contribution on

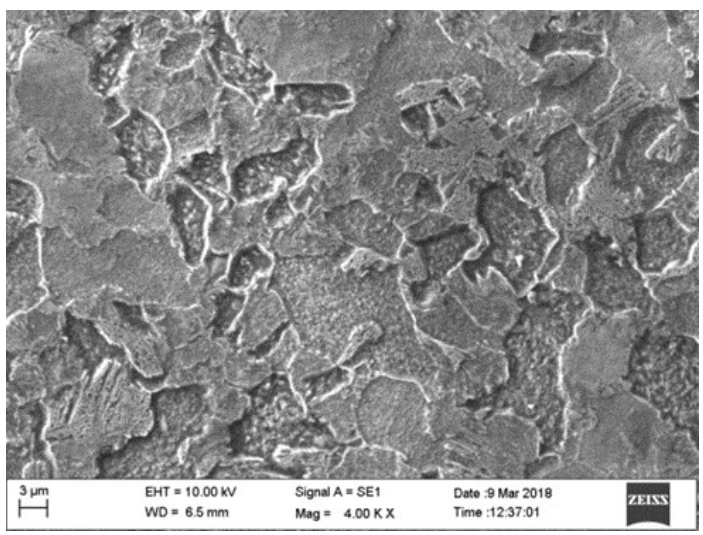

Figure 4. Ferrite-martensite DPS at $790^{\circ} \mathrm{C}$.

Table 2. $\mathrm{T}_{\mathrm{L}}$ and $\mathrm{S}_{\mathrm{R}}$ of AISI1040 F-M DPS.

\begin{tabular}{|c|c|c|c|c|c|c|}
\hline S1 No & Temperature $\left({ }^{\circ} \mathrm{C}\right)$ & Speed $(\mathrm{m} / \mathrm{min})$ & Feed $(\mathrm{mm} / \mathrm{rev})$ & $\mathrm{DoC}(\mathrm{mm})$ & $\mathrm{T}_{\mathrm{L}}(\mathrm{s})$ & $\mathrm{S}_{\mathrm{R}}(\mu \mathrm{m})$ \\
\hline 1 & 750 & 80 & 0.13 & 0.2 & 2098 & 4.07 \\
\hline 2 & 750 & 80 & 0.13 & 0.2 & 2138 & 4.05 \\
\hline 3 & 750 & 80 & 0.13 & 0.2 & 2145 & 4.00 \\
\hline 4 & 750 & 115 & 0.15 & 0.4 & 1305 & 3.62 \\
\hline 5 & 750 & 115 & 0.15 & 0.4 & 1301 & 3.56 \\
\hline 6 & 750 & 115 & 0.15 & 0.4 & 1321 & 3.67 \\
\hline 7 & 750 & 150 & 0.18 & 0.6 & 411 & 3.07 \\
\hline 8 & 750 & 150 & 0.18 & 0.6 & 405 & 3.21 \\
\hline 9 & 750 & 150 & 0.18 & 0.6 & 420 & 3.09 \\
\hline 10 & 770 & 80 & 0.15 & 0.6 & 1041 & 4.02 \\
\hline 11 & 770 & 80 & 0.15 & 0.6 & 1054 & 4.089 \\
\hline 12 & 770 & 80 & 0.15 & 0.6 & 1059 & 4.07 \\
\hline 13 & 770 & 115 & 0.18 & 0.2 & 1023 & 2.99 \\
\hline 14 & 770 & 115 & 0.18 & 0.2 & 1046 & 2.98 \\
\hline 15 & 770 & 115 & 0.18 & 0.2 & 1045 & 2.96 \\
\hline 16 & 770 & 150 & 0.13 & 0.4 & 543 & 2.49 \\
\hline 17 & 770 & 150 & 0.13 & 0.4 & 598 & 2.39 \\
\hline 18 & 770 & 150 & 0.13 & 0.4 & 568 & 2.45 \\
\hline 19 & 790 & 80 & 0.18 & 0.4 & 698 & 2.66 \\
\hline 20 & 790 & 80 & 0.18 & 0.4 & 686 & 2.67 \\
\hline 21 & 790 & 80 & 0.18 & 0.4 & 693 & 2.66 \\
\hline 22 & 790 & 115 & 0.13 & 0.6 & 235 & 2.92 \\
\hline 23 & 790 & 115 & 0.13 & 0.6 & 245 & 2.95 \\
\hline 24 & 790 & 115 & 0.13 & 0.6 & 226 & 2.90 \\
\hline 25 & 790 & 150 & 0.15 & 0.2 & 398 & 2.16 \\
\hline 26 & 790 & 150 & 0.15 & 0.2 & 393 & 2.14 \\
\hline 27 & 790 & 150 & 0.15 & 0.2 & 387 & 2.17 \\
\hline
\end{tabular}


Table 3. ANOVA for $T_{L}$.

\begin{tabular}{cccccc}
\hline Factors & Degree of freedom & Seq sum of square & Adj MS & P & \% Contribution \\
\hline Temperature $\left({ }^{\circ} \mathrm{C}\right)$ & 2 & 3199142 & 1599571 & $<0.001$ & 38.11 \\
\hline Speed $(\mathrm{m} / \mathrm{min})$ & 2 & 3116934 & 1558467 & $<0.001$ & 31.14 \\
\hline Feed $(\mathrm{mm} / \mathrm{rev})$ & 2 & 342628 & 171314 & $<0.001$ & 4.08 \\
\hline DoC $(\mathrm{mm})$ & 2 & 1730726 & 865363 & $<0.001$ & 20.62 \\
\hline Error & 18 & 1932 & 220 & & \\
\hline Total & 26 & 8393396 & & & \\
\hline
\end{tabular}

Table 4. ANOVA for $\mathrm{S}_{\mathrm{R}}$.

\begin{tabular}{cccccc}
\hline Factors & Degree of freedom & Seq sum of square & Adj MS & P & \% Contribution \\
\hline Temperature $\left({ }^{\circ} \mathrm{C}\right)$ & 2 & 5.0471 & 2.52356 & $<0.001$ & 46.54 \\
\hline Speed $(\mathrm{m} / \mathrm{min})$ & 2 & 4.5004 & 2.25020 & $<0.001$ & 41.50 \\
\hline Feed $(\mathrm{mm} / \mathrm{rev})$ & 2 & 0.5110 & 0.25550 & $<0.001$ & 4.71 \\
\hline DoC $(\mathrm{mm})$ & 2 & 0.5474 & 0.27371 & $<0.001$ & 5.05 \\
\hline Error & 18 & 0.2331 & 0.01327 & & \\
\hline Total & 26 & 10.84 & & & \\
\hline
\end{tabular}

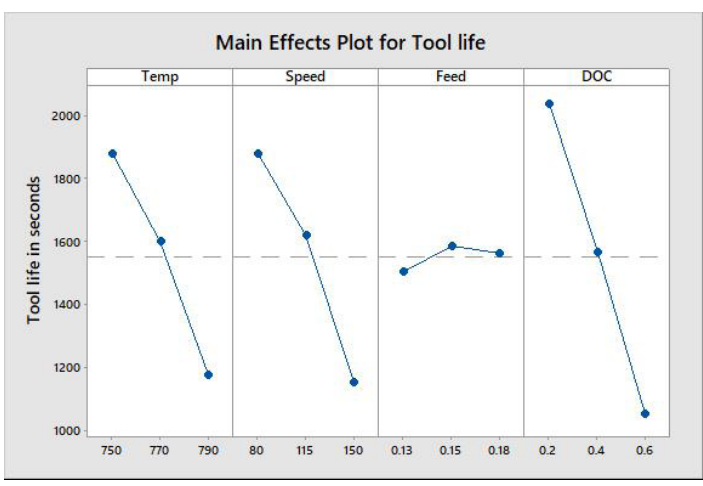

Figure 5. Main effect plots for $T_{L}$.

$\mathrm{T}_{\mathrm{L}}$ and $\mathrm{S}_{\mathrm{R}}$, whereas depth of cut has least contribution on $\mathrm{S}_{\mathrm{R}}$ and moderate on $\mathrm{T}_{\mathrm{L}}$.

$S_{R}$ is an important factor for machined components. Main effect plot (Figure 6) shows the effect of independent factors effect on the dependent factor (surface roughness). Temperature and speed are having highest contribution on the $S_{R}$ of DPS. Feed and DoC have marginal effect on $S_{R}$ (Table 4 and Figure 6). In a dual phase condition as the intercritical temperature increases from 750 to $790^{\circ} \mathrm{C}$ which reduces the ferrite and increase the quantity of martensite. Ferrite is softer in nature and martensite is harder but combination of both leads to improve the machinability of the DPS. the weight percentage of dual phases, size and shape of individual phases quality and quantity of the DPS helps to improve the surface roughness. The increases the tetragonality of BCT martensite cell to form maximum distortion in the lattice and atomic cluster of martensite is which increases hardness of the martensite. For this reason, at lower critical temperature results shows lesser surface finish compare to higher intercitical temperature.

\subsection{Error analysis for $T_{L}$ and $S_{R}$ of AISI1040 F-M DPS}

Statistical analysis is validated through regression equations to confirm the test results. Actual test results of $T_{L}$ and $S_{R}$ values are compared with the predicted results

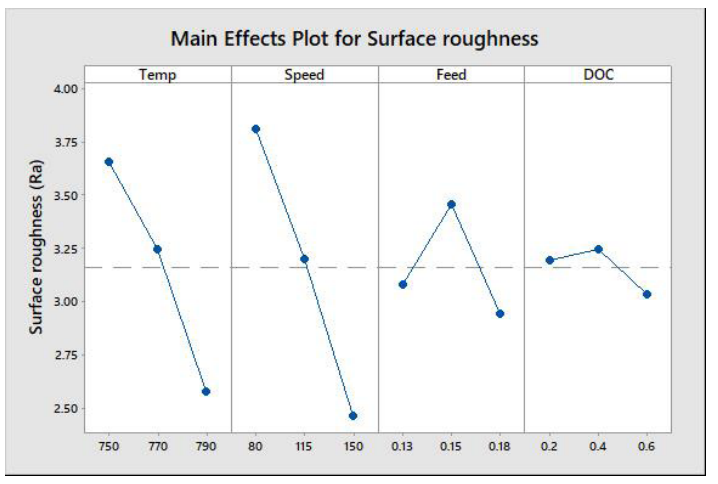

Figure 6. Main effect plots for $S_{R}$.

of regression equations. Difference between the actual and predicted results is shown as \% Error.

Figures 7 and 8 show the error analysis for $T_{L}$ and $S_{R}$ respectively. It is observed that predicted and actual results are approximately same for all the test trials. Difference of predicted and actual results are minimal, and it confirms the R-Square values obtained for $T_{L}$ and $S_{R}$. The experimental results recorded prove that regression equations obtained for this study may be used to predict $\mathrm{T}_{\mathrm{L}}$ and $\mathrm{S}_{\mathrm{R}}$.

\subsection{Optimization of process parameters for AISI1040 F-M DPS}

Optimization is carried out by using response surface optimization technique for all machining variables and temperatures. Optimization is performed to get better $T_{L}$ and $S_{R}$ of heat treated steel. Larger $T_{L}$ and lower $S_{R}$ are the requirement in machining. By combining both $T_{L}$ and $S_{R}$ better machinability can be achieved.

Figure 9 shows the detailed response optimization of $T_{L}$ and $S_{R}$ values. From the results, in order to obtain the optimum combination of $T_{L}$ and $S_{R}$ values RSM is used. Accordingly, values for different machining parameters are obtained. The composite desirability, D value of 0.9555 shows that the obtained optimized results have good fit. Optimum $\mathrm{T}_{\mathrm{L}}$ and $\mathrm{S}_{\mathrm{R}}$ have been observed at $770{ }^{\circ} \mathrm{C}$ temperature treated dual phase AISI1040 steel. Considering speed, feed and 


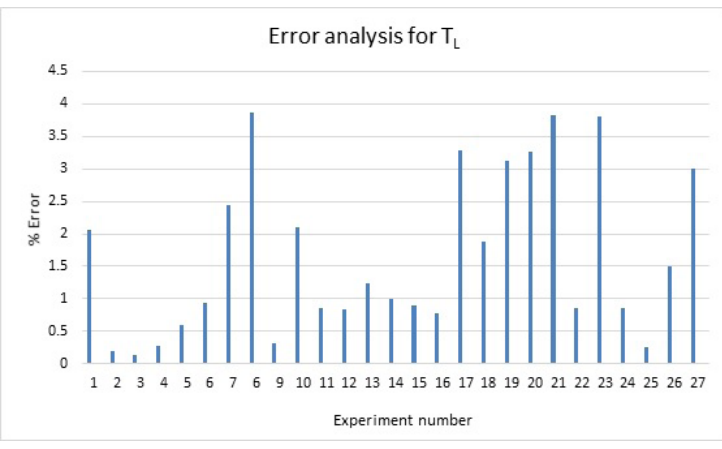

Figure 7. Error analysis for $\mathrm{T}_{\mathrm{L}}$ of AISI1040 F-M DPS.

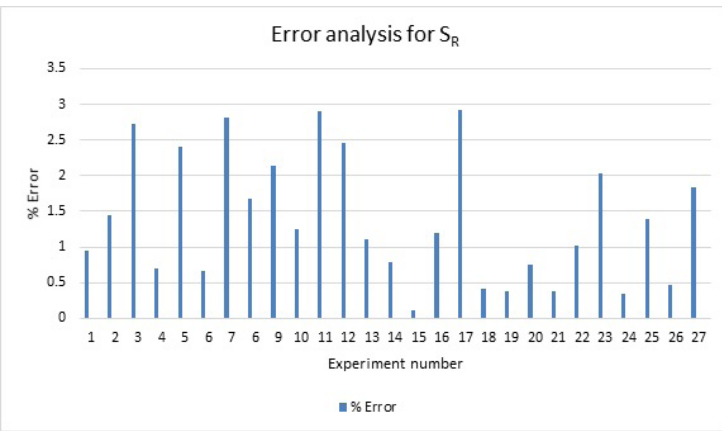

Figure 8. Error analysis for $\mathrm{S}_{\mathrm{R}}$ of AISI1040 F-M DPS.

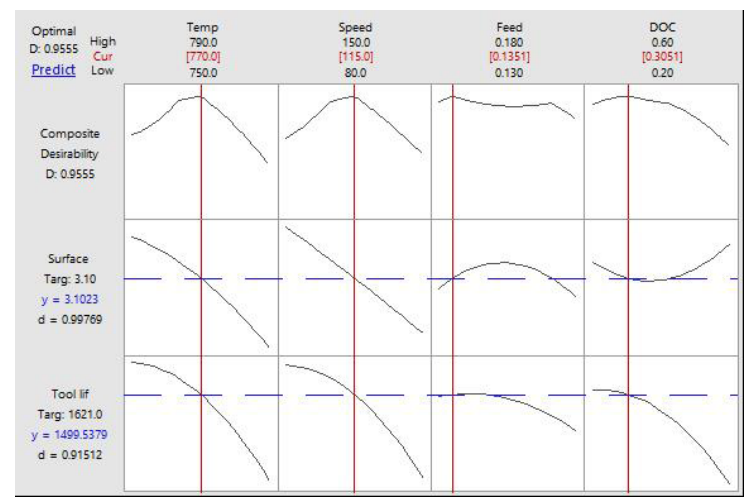

Figure 9. Response surface plots for $\mathrm{T}_{\mathrm{L}}$ and $\mathrm{S}_{\mathrm{R}}$ of AISI1040 F-M DPS.

DoC as turning parameters, confirmation test is carried out at the optimized parameter level to determine the feasibility of the model. By analyzing both $\mathrm{T}_{\mathrm{L}}$ and surface roughness, experiment results $\mathrm{T}_{\mathrm{L}}$ as 1492 seconds and from RSM optimized parameter as 1499.53 seconds. This shows that actual and optimized values are closer and within the range. $\mathrm{S}_{\mathrm{R}}$ obtained by considering the optimized process parameters, the experimental value of $\mathrm{S}_{\mathrm{R}}$ is $3.11 \mu \mathrm{m}$ and optimized process result is $3.10 \mu \mathrm{m}$. Difference between actual and optimized values in $\mathrm{T}_{\mathrm{L}}$ and $\mathrm{S}_{\mathrm{R}}$ is less than $5 \%$ error. Hence the hypothesis is correct.

\section{Conclusion}

Following conclusion are arrived after conducting machining tests on DPS.
1. Better $T_{L}$ was obtained for the DPS, heat treated at the lower interitical temperature of $750{ }^{\circ} \mathrm{C}$. Misconstrue shows the formation of dual phase depending on the intercritical temperature.

2. Experiential and statistical results revealed that speed and depth of cut are major contribution factors on $\mathrm{T}_{\mathrm{L}}$ and $\mathrm{S}_{\mathrm{R}}$.

3. Increase in the cutting speed has resulted in the reduction of $T_{L}$. Cutting speed has also major contribution on the variation of surface roughness.

4. With increase in depth of cut, $T_{L}$ decreases due to enhancement in tool wear as the contact area between tool and work material increases.

5. Increase in the cutting speed has resulted in the reduction of roughness value and smooth surface is obtained at higher speeds with minimum depth of cut.

6. The effect of the cutting speed and depth of cut on $T_{L}$ is more pronounced, than the effect of feed.

7. RSM and its validation results confirm optimum $T_{L}$ of 1492 seconds and 3.11 microns as $S_{R}$ for F-M dual phase. The composite desirability $\mathrm{D}$ value of 0.955 (near to 1 ) shows that the obtained optimized results have good fit at intercritical temperature of $770{ }^{\circ} \mathrm{C}$.

\section{References}

1. Adamczyk J, Grajcar A. Heat treatment and mechanical properties of low-carbon steel with dual-phase microstructure. J Achiev Mater Manuf Eng. 2007;22(1):13-20.

2. Tukur S, Usman MM, Muhammad I, Sulaiman NA. Effect of tempering temperature on mechanical properties of medium carbon steel. Int J Eng Trends Technol. 2014;9(15):798-800.

3. Oluyemia DO, Oluwole OI, Adewuyi BO. Studies of the properties of heat treated rolled medium carbon steel. Mater Res. 2011;14(2):135-41. http://dx.doi.org/10.1590/S151614392011005000040 .

4. Gurumurthy BM, Gowrishankar MC, Sharma S, Kini A, Shettar M, Hiremath P. Microstructure authentication on mechanical property of medium carbon Low alloy duplex steels. J Mater Res Technol. 2020;9(3):5105-11.

5. Lee WS, Su TT. Mechanical properties and microstructural features of AISI 4340 high-strength alloy steel under quenched and tempered conditions. J Mater Process Technol. 1999;87(13):198-206. http://dx.doi.org/10.1016/S0924-0136(98)00351-3.

6. Shahreza ZS, Dini G, Taherizadeh A. Improving the microstructure, mechanical and magnetic properties of AISI 4340 steel using the heat treatment process. Int J Iron Steel Soc Iran. 2013;10(2):1822.

7. Concepción VL, Lorusso HN, Svoboda HG. Effect of carbon content on microstructure and mechanical properties of dual phase steels. Procedia Mater Sci. 2015;8:1047-56.

8. Ghaheri A, Shafyei A, Honarmand M. Effects of inter-critical temperatures on martensite morphology, volume fraction and mechanical properties of dual-phase steels obtained from direct and continuous annealing cycles. Mater Des. 2014;62:305-19. http://dx.doi.org/10.1016/j.matdes.2014.04.073.

9. Banerjee N, Sharma A. Identification of a friction model for minimum quantity lubrication machining. J Clean Prod. 2014;83:437-43.

10. Khrais SK, Lin YJ. Wear mechanisms and tool performance of TiAIN PVD coated inserts during machining of AISI 4140 
steel. Wear. 2007;262(1-2):64-9. http://dx.doi.org/10.1016/j. wear.2006.03.052.

11. Das SR, Dhupal D, Kumar A. Experimental investigation into machinability of hardened AISI 4140 steel using TiN coated ceramic tool. Meas J Int Meas Confed. 2015;62:108-26.

12. Balabhadra N, Ugender S. Effects of cutting variables on MRR and tool wear for EN8 medium. Int J Innov. 2015;2(11):653-6.

13. Anand PL, Shivade S, Bhagat S, Jagdale S, Nikam A. Optimization of machining parameters for turning using taguchi approach. Int J Recent Technol Eng. 2014;3(1):145-9.

14. Puneet NP, Bhat PV, Abdulla MJ. Flank wear analysis in turning of EN8 steel for different tool inserts. SSRG Int J Eng Trends Technol. 2016;(1):119-122.

15. Sathiyaraj S, Elanthiraiyan A, Haripriya G, Pari VS. Optimization of machining parameters for EN8 steel through Taguchi method. J Chem Pharm Sci. 2015;2015:157-61.

16. Banerjee N, Sharma A. A comprehensive assessment of minimum quantity lubrication machining from quality, production, and sustainability perspectives. Sustain Mater Technol. 2018;17:e0070.

17. Baskar N, Vaiysnavan R, Prabhu R, Prakash R, Kumar TN. Optimization of machining parameters on en 8 material using genetic algorithm. Int J Eng Res Technol. 2018;6(7):1-5.

18. Sunil Raykara J, D'Addona DM, Kramar D. Analysis of surface topology in dry machining of EN-8 Steel. Proc Mater Sci. 2014;6:931-8.
19. Bhuyan RK, Akula PK, Chivukula GR, Sai BM. Comparative study of the machining characteristics of EN24 and hardened EN24 during CNC turning. Int J Mech Eng. 2018;9(4):556-64.

20. Banerjee N, Sharma A. Improving machining performance of Ti-6Al-4V through multi-point minimum quantity lubrication method. Proc Inst Mech Eng, B J Eng Manuf. 2019;233(1):32136.

21. Dhar NR, Paul S, Chattopadhyay AB. The influence of cryogenic cooling on tool wear, dimensional accuracy and surface finish in turning AISI 1040 and E4340C steels. Wear. 2001;249(1011):932-42.

22. Aslan E, Camuşcu N, Birgören B. Design optimization of cutting parameters when turning hardened AISI 4140 steel $(63 \mathrm{HRC})$ with A12O3 + TiCN mixed ceramic tool. Mater Des. 2007;28(5):161822. http://dx.doi.org/10.1016/j.matdes.2006.02.006.

23. Patel US, Rawal SK, Arif AFM, Veldhuis SC. Influence of secondary carbides on microstructure, wear mechanism, and tool performance for different cermet grades during highspeed dry finish turning of AISI 304 stainless steel. Wear. 2020;452:203285.

24. Pierman AP, Bouaziz O, Pardoen T, Jacques PJ, Brassart L. The influence of microstructure and composition on the plastic behaviour of dual-phase steels. Acta Mater. 2014;73:298-311. http://dx.doi.org/10.1016/j.actamat.2014.04.015.

25. Gurumurthy BM, Sharma SS, Kini UA. Ferrite-martensite dual phase treatment of AISI 1040 steel and mechanical characterization. Key Eng Mater. 2017;748:280-3. 